\title{
Electrochemical Exfoliation of Graphite: Effect of Temperature and Hydrogen Peroxide Addition
}

\author{
Shaikh T. Hossain ${ }^{1}$ and Ruigang Wang ${ }^{1,2,3, *}$ \\ Materials Science and Engineering Program ${ }^{1}$ and Department of Chemistry ${ }^{2}$, \\ Youngstown State University, Youngstown, OH 44555 \\ Department of Metallurgical and Materials Engineering ${ }^{3}$, The University of Alabama, \\ Tuscaloosa, AL 35487
}

\begin{abstract}
:
Controlling the defect density in graphene is critical to manipulate materials properties and functionality through synthesis and processing. In this work, graphene was prepared by electrochemical exfoliation method at different temperatures from 25 to $95{ }^{\circ} \mathrm{C}$ with and without the addition of $\mathrm{H}_{2} \mathrm{O}_{2}$. The effect of both the exfoliation temperature and $\mathrm{H}_{2} \mathrm{O}_{2}$ addition on governing the defect density and oxygen functional groups in graphene was investigated using Raman spectroscopy analysis and thermogravimetric analysis (TGA), respectively. The number of defects, which can be edge defect or oxygen functional groups, decreases with the increase of exfoliation temperature from 25 to $95{ }^{\circ} \mathrm{C}$. This can be explained by nucleophilicity of hydroxyl ions and peroxide ions. The thermal stability of the as-synthesized graphene increases with increasing exfoliation temperature and the amount of $\mathrm{H}_{2} \mathrm{O}_{2}$ addition. Transmission electron microscopy (TEM) was performed to characterize the morphology and the layer number of the as-synthesized graphene.
\end{abstract}

\section{Introduction:}

The wonder material called graphene, which is a two-dimensional monolayer carbon material arranged in a hexagonal lattice, is rapidly getting more attention since 2004 due to its superior electrical, thermal, optical properties and high surface area. ${ }^{1,2,3}$ Great efforts have been made to synthesize high quality and low-defect density graphene for various applications, such as energy storage and conversion devices, ${ }^{4,5}$ composite materials, ${ }^{6}$ semiconductor devices, ${ }^{7,8}$ and sensors. ${ }^{9}$ Different methods, such as chemical vapor deposition (CVD), ${ }^{10,11,12}$ micromechanical exfoliation, ${ }^{13}$ sonochemical liquid phase exfoliation, ${ }^{14}$ microwave, ${ }^{15,16}$ Hummers method, ${ }^{17}$ Tour method, ${ }^{18}$ and electrochemical exfoliation ${ }^{19,20}$ etc. have been used to make low-defect graphene. Among these, Hummers and Tour methods are used to produce graphene oxide first by chemically exfoliating, and then it needs to be reduced chemically or thermally to reestablish electronic properties. After reduction of graphene oxide, reduced graphene can still have a large number of defects. ${ }^{18}$ CVD method, which is not cost effective, can be useful to yield better quality graphene. ${ }^{19}$ Kim et al. ${ }^{21}$ conducted work on surface wave plasma CVD to synthesize graphene at low temperature $\left(400^{\circ} \mathrm{C}\right)$, which had a large amount of defects as shown in their Raman spectra. 
Parvez et al. ${ }^{19}$ studied the electrochemical exfoliation of graphite using different aqueous inorganic salts, such as ammonium sulfate, ammonium chloride, sodium sulfate, sodium nitrate, potassium sulfate and sodium chlorate as the electrolyte. They suggested that sulfate ions showed better exfoliation even at low reduction voltage. A high yield (>85\%, $\leq 3$ layers) with an improved chemical and electronic properties of graphene were obtained at room temperature by electrochemical exfoliation. Sanjeeva et al. ${ }^{20}$ investigated the electrochemical exfoliation behavior of graphite, using sodium hydroxide with the addition of hydrogen peroxide $\left(\mathrm{H}_{2} \mathrm{O}_{2}\right)$ as an electrolyte solution. They proposed that addition of hydrogen peroxide can yield better exfoliation process and produce multilayered, low-defect graphene. However, it is still challenging to produce single layer low-defect graphene using electrochemical exfoliation method. The increasing temperature during exfoliation can give extra energy to speed up the reaction rate of hydrogen peroxide with hydroxyl ions, which can be a key to produce highquality graphene. The information available in the literature seems insufficient on the electrochemical exfoliation of graphite to synthesize graphene at elevated temperature. In this project, we investigated the electrochemical exfoliation process of graphite at different temperatures with and without the addition of $\mathrm{H}_{2} \mathrm{O}_{2}$.

\section{Experimental:}

\subsection{Materials synthesis:}

The electrolyte solution was prepared using $1.06 \mathrm{~g}\left(\mathrm{NH}_{4}\right)_{2} \mathrm{SO}_{4}$ in $80 \mathrm{~mL}$ DI water. ${ }^{19}$ The solution was stirred for $1 \mathrm{~min}$ on a magnetic stirrer. Then $5 \mathrm{~mL}$ or $10 \mathrm{~mL} \mathrm{H}_{2} \mathrm{O}_{2}$ was added to make different solutions and, in some cases, no $\mathrm{H}_{2} \mathrm{O}_{2}$ was used. The solutions were kept at different temperatures $\left(25,50,75,95^{\circ} \mathrm{C}\right)$ in a heated water bath. The maximum water bath temperature of $95{ }^{\circ} \mathrm{C}$ was used because boiling temperature of water is about $100{ }^{\circ} \mathrm{C}$, and $\mathrm{H}_{2} \mathrm{O}_{2}$ in aqueous solution starts to decompose at $114{ }^{\circ} \mathrm{C}$. Two graphite rods were used as cathode and anode, serving as the carbon source for each electrolyte solution. The rods were dipped into the solutions at a distance of $4 \mathrm{~cm}$ between them as shown in Figure 1. The graphite rods were connected to the negative and positive source from a BK Precision 1760a triple output DC power supply. To start the electrochemical exfoliation on positive rods, $10 \mathrm{~V}$ of power was supplied and the process was conducted for $2 \mathrm{hrs}$. Then the solution was cooled down to room temperature if in case it was heated. The samples were filtered and washed with DI water several times to remove any ammonium ion left in graphene. Finally, the samples were dried at $75{ }^{\circ} \mathrm{C}$ for $12 \mathrm{hrs}$. The samples are designated as EG- $\mathrm{XH}_{2} \mathrm{O}_{2}-\mathrm{T}$ or $\mathrm{EG}-\mathrm{XH}_{2} \mathrm{O}_{2}$, where $\mathrm{EG}$ is exfoliated graphene, $\mathrm{X}$ is the amount of $\mathrm{H}_{2} \mathrm{O}_{2}$ addition, and $\mathrm{T}$ is the solution temperature. $\mathrm{EG}-\mathrm{XH}_{2} \mathrm{O}_{2}$ is referred to the samples for EG synthesized with the addition of $\mathrm{X} \mathrm{mL}$ of $\mathrm{H}_{2} \mathrm{O}_{2}$ at different temperatures.

\subsection{Characterization:}

The X-ray diffraction (XRD) of powder samples was conducted in Rigaku MiniFlex II from $5^{\circ}$ to $90^{\circ}$ of $2 \theta$ with a scan rate of $0.5^{\circ}$ per min. Horiba iHR320 Raman spectrometer was used to 
record Raman spectrum with a laser at an excitation wavelength of $532 \mathrm{~nm}$. The 5-second exposure time and 10 spectrum accumulation number were used for each of the samples. Before the measurement, the spectrometer was calibrated, using a Si single crystal wafer as a reference peaked at $520 \mathrm{~cm}^{-1}$. TA Q50 Thermogravimetric analyzer (TGA) was used to test thermal stability of the as-synthesized samples. TGA was done from room temperature to $900{ }^{\circ} \mathrm{C}$ at a temperature ramp rate of $10{ }^{\circ} \mathrm{C} / \mathrm{min}$ under nitrogen atmosphere. JEOL 2100 Transmission electron microscope (TEM) at an acceleration voltage of $200 \mathrm{KV}$ was used to investigate the morphology and structure of the samples. The powder samples were added in ethanol and then were sonicated for 30 seconds. Holey carbon copper grids from Ted Pella were dipped into the solutions to prepare TEM samples.

\section{Results and Discussion:}

\subsection{Production amount and XRD analysis:}

As described earlier, each experiment was conducted for $2 \mathrm{hrs}$ under different conditions. The surface area of immersed graphite rods was $782 \mathrm{~mm}^{2}$. When the experiment was conducted at high temperature, the surface area decreased gradually due to the evaporation of water. Table 1 shows the amount of produced graphene by electrochemical exfoliation process under different conditions. The production of graphene increases from $223 \mathrm{mg}$ to $276 \mathrm{mg}$ as the amount of the addition of $\mathrm{H}_{2} \mathrm{O}_{2}$ increases from 0 to $10 \mathrm{~mL}$ in the solution at $25{ }^{\circ} \mathrm{C}$. Similar increment can be seen for the temperatures at 50,75 and $95{ }^{\circ} \mathrm{C}$. This increment in production happens due the increasing of the exfoliation rate, which is described later. The production of graphene starts decreasing as the temperatures are increased for the same amount of $\mathrm{H}_{2} \mathrm{O}_{2}$ addition. This occurs due to the decrease of the surface area of immersed graphite rods.

Figure 2 displays the XRD patterns of graphite and as-prepared graphene synthesized at $95{ }^{\circ} \mathrm{C}$ with and without the addition of $\mathrm{H}_{2} \mathrm{O}_{2}$. For graphite, three peaks are found at $2 \theta$ of $26.5^{\circ}, 44.5^{\circ}$ and $54.4^{\circ}$ for the corresponding planes (002), (101) and (004), respectively. ${ }^{22}$ A single peak with very low intensity compared to a similar peak of graphite is found at $2 \theta=26.6^{\circ}$ for each graphene sample. ${ }^{23,24}$ This peak suggests that as-prepared graphene sheets have either good crystallinity or multiple layers. ${ }^{25}$ Wazir et al. ${ }^{26}$ and Sun et al. ${ }^{27}$ showed a broad peak at $2 \theta=26.5^{\circ}$ for graphene layers. This broad peak can be a proof of the presence of amorphous graphene layers. Thus, XRD patterns of graphene can be ambiguous and because of this researchers have been relying on other characterization techniques, such as Raman and TEM analysis, to verify more precisely the presence of a single or multi-layers graphene.

\subsection{Raman analysis:}

Raman spectroscopy was carried out to characterize the defect-activated band information in exfoliated graphene (EG). Raman spectra are shown in Figure 3. Raman spectra of EG synthesized without the addition of $\mathrm{H}_{2} \mathrm{O}_{2}\left(\mathrm{EG}-\mathrm{OH}_{2} \mathrm{O}_{2}\right)$ are displayed in Figure 3a. There are three major peaks at 1325, 1568 and $2736 \mathrm{~cm}^{-1}$, which are called D band, G band, and 2D band, 
respectively. ${ }^{28} \mathrm{D}$ peak at $1325 \mathrm{~cm}^{-1}$ is activated due to different kinds of disordered defects, such as edges, functional groups and structural groups. ${ }^{29} \mathrm{G}$ peaks at $1568 \mathrm{~cm}^{-1}$ correspond to transverse optical (TO) and longitudinal optical (LO) phonon mode. ${ }^{20}$ The intensity of D band and $\mathrm{G}$ band decreases with increasing the electrolyte solution temperatures as shown in Figure 3a. A small D-band peak typically suggests a low concentration of disorder structures in graphene and/or a high purity of graphene, indicating that increasing the electrolyte solution temperature during the electrochemical exfoliation process resulted in a better quality of graphene. This is also confirmed by the following TGA analysis. The ratio of the intensity of D and $\mathrm{G}$ band decreases with increasing the temperature. The peak at $2170 \mathrm{~cm}^{-1}$ corresponds to the linear carbon chains. ${ }^{30,31}$ However, carbon chains are not stable in air at room temperature. ${ }^{31}$ The Raman $\mathrm{G}^{*}$ bands found at $2355 \mathrm{~cm}^{-1}$ are attributed to the combination of two phonon modes: inplane longitudinal acoustic (iLA) and in-plane transverse optical (iTO) modes. The position of $\mathrm{G}^{*}$ bands do not change for few layers of graphene; though, $\mathrm{G}^{*}$ bands can shift to the left for graphite due to a large amount of layers. ${ }^{32}$ Another important peak $2 \mathrm{D}$ found at $2736 \mathrm{~cm}^{-1}$ is the second order two-phonon process. The observed single 2D band suggests that the samples have single or few layers of graphene. ${ }^{29}$ Figures $3 b$ and $3 c$ show Raman spectra of the EG synthesized with the addition of $5 \mathrm{~mL}\left(\mathrm{EG}-5 \mathrm{H}_{2} \mathrm{O}_{2}\right)$ and $10 \mathrm{~mL} \mathrm{H} \mathrm{H}_{2} \mathrm{O}_{2}\left(\mathrm{EG}-10 \mathrm{H}_{2} \mathrm{O}_{2}\right)$, respectively. These figures show a similar trend as shown in Figure $3 \mathrm{a}$ for the samples without addition of $\mathrm{H}_{2} \mathrm{O}_{2}$.

The intensity ratio of $\mathrm{D}$ and $\mathrm{G}$ band relates to the mean distance between defects $\left(\mathrm{L}_{\mathrm{D}}\right)$. It can be estimated by using the equation below. ${ }^{33}$

$$
\mathrm{L}_{\mathrm{D}}^{2}\left(\mathrm{~nm}^{2}\right)=(1.8 \pm 0.5) \times 10^{-9} \lambda^{4}\left(\mathrm{I}_{\mathrm{D}} / \mathrm{I}_{\mathrm{G}}\right)^{-1}
$$

Here, $\lambda$ is the excitation laser wavelength in $\mathrm{nm}$, and $\mathrm{I}_{\mathrm{D}}$ and $\mathrm{I}_{\mathrm{G}}$ are the intensity of $\mathrm{D}$ band and $\mathrm{G}$ band, respectively. Furthermore, the number of defects $\left(\mathrm{N}_{\mathrm{D}}\right)$ can also be estimated based on the equation below. ${ }^{33}$

$$
\mathrm{N}_{\mathrm{D}}\left(\mathrm{cm}^{-2}\right)=10^{14} /\left(\pi \mathrm{L}_{\mathrm{D}}^{2}\right)
$$

Figure 4a shows that the mean distance between defects increases with increasing the electrolyte solution temperatures for the samples with and without the addition of $\mathrm{H}_{2} \mathrm{O}_{2}$. The EG- $0 \mathrm{H}_{2} \mathrm{O}_{2}$ has the lowest $\mathrm{L}_{\mathrm{D}}$ value at room temperature. As the temperature of electrolyte solution increases, the $\mathrm{L}_{\mathrm{D}}$ value for the $\mathrm{EG}-\mathrm{OH}_{2} \mathrm{O}_{2}$ starts increasing more rapidly than it does for both $\mathrm{EG}-5 \mathrm{H}_{2} \mathrm{O}_{2}$ and EG- $10 \mathrm{H}_{2} \mathrm{O}_{2}$. Thus, EG- $0 \mathrm{H}_{2} \mathrm{O}_{2}$ has the highest $\mathrm{L}_{\mathrm{D}}$ value compared to the $\mathrm{L}_{\mathrm{D}}$ value for the $\mathrm{EG}$ synthesized with the addition of $\mathrm{H}_{2} \mathrm{O}_{2}\left(\mathrm{EG}-5 \mathrm{H}_{2} \mathrm{O}_{2}\right.$ and $\left.\mathrm{EG}-10 \mathrm{H}_{2} \mathrm{O}_{2}\right)$ for each of the following temperatures: 50, 75 and $95{ }^{\circ} \mathrm{C}$. The number of defect $\left(\mathrm{N}_{\mathrm{D}}\right)$ decreases with increasing the electrolyte solution temperatures for all three samples shown in Figure 4b. This illustrates the exactly opposite trend of the mean distance between defects shown in Figure 4a. In other words, EG- $0 \mathrm{H}_{2} \mathrm{O}_{2}$ has the lowest $\mathrm{N}_{\mathrm{D}}$ value at 50,75 and $95{ }^{\circ} \mathrm{C}$. This can be explained by the effectiveness of interaction of different ions with graphite discussed later. The ratios of $I_{D}$ and $I_{G}$ for the graphene synthesized at the electrolyte solution temperature of $95^{\circ} \mathrm{C}$ with addition of 0,5 
and $10 \mathrm{~mL} \mathrm{H}_{2} \mathrm{O}_{2}$ are $0.32,0.39$ and 0.38 , respectively, which are significantly lower than for those in the graphene prepared by either chemically or thermally reduction of graphene oxide $(1.1 \sim 1.4)^{34}$ and in electrochemically exfoliated graphene at room temperature $(0.67) .{ }^{20}$ Since the ratio of $I_{D}$ and $I_{G}$ is related to the defect density of graphene, it can be concluded that the graphene synthesized at a higher electrolyte solution temperature in electrochemical exfoliation method shows lower defect density than the graphene synthesized using other methods.

\subsection{Thermogravimetric analysis:}

To further understand the effect of $\mathrm{H}_{2} \mathrm{O}_{2}$ addition and exfoliation temperature, TGA was carried out to evaluate the thermal stability and decomposition of the residual functional groups in the as-synthesized graphene shown in Figures 5 and 6. Figure 5 depicts the TGA and first derivative (DTG, the rate of change of mass) curves of EG- $0 \mathrm{H}_{2} \mathrm{O}_{2}-25$, where three major weight loss steps are observed. As shown in Figure 5, the sample initially undergoes the first major weight loss of $4.9 \%$ below $150{ }^{\circ} \mathrm{C}$ due to the water removal. Then, the second weight loss occurs between 150 $400{ }^{\circ} \mathrm{C}$ centered at $184{ }^{\circ} \mathrm{C}$ with an observed weight loss of $15.2 \%$ corresponding to the removal of oxygen functional groups, such as $-\mathrm{OH}$ and $=\mathrm{O} .{ }^{35}$ Chen et al. ${ }^{36}$ Park et al. ${ }^{37}$ and Naebe et al. ${ }^{38}$ showed that oxygen functional groups were removed over $200{ }^{\circ} \mathrm{C}$ for both graphene and graphene oxide. No obvious weight loss is observed from 400 to $500{ }^{\circ} \mathrm{C}$. The third weight loss step is detected at over $600{ }^{\circ} \mathrm{C}$, which relates to the unstable carbon remaining in the structure. ${ }^{35}$

Figure 6a compares the thermal stability of EG- $0 \mathrm{H}_{2} \mathrm{O}_{2}$ at different exfoliation temperatures: 25 , 50,75 and $95{ }^{\circ} \mathrm{C}$. Clearly, the sample obtained at $25{ }^{\circ} \mathrm{C}$ reveals the highest weight loss of $\sim 50 \%$ up to $880{ }^{\circ} \mathrm{C}$ and other samples obtained at higher temperatures $\left(50,75,95{ }^{\circ} \mathrm{C}\right)$ exhibits a much smaller weight loss. The sample obtained at $95{ }^{\circ} \mathrm{C}$ demonstrates the best thermal stability and only shows $\sim 1 \%$ weight loss in this temperature range. It can be concluded that the weight loss of the EGs synthesized without the addition of $\mathrm{H}_{2} \mathrm{O}_{2}$ decreases with increasing the exfoliation temperature. The samples obtained at 50 and $75{ }^{\circ} \mathrm{C}$ exhibit a similar three major steps of weight loss compared to the sample obtained at $25{ }^{\circ} \mathrm{C}$ as discussed above in Figure 5. The sample acquired at $90{ }^{\circ} \mathrm{C}$ shows a continuous weight loss with a relatively small weight change $(\sim 1 \%)$ below $700{ }^{\circ} \mathrm{C}$ seen in Figure 6d, which demonstrates high thermal stability up to $880{ }^{\circ} \mathrm{C}$. Figures $6 \mathrm{~b}$ and $6 \mathrm{c}$ display the thermal stability of $\mathrm{EG}-5 \mathrm{H}_{2} \mathrm{O}_{2}$ and $\mathrm{EG}-10 \mathrm{H}_{2} \mathrm{O}_{2}$ which were synthesized at the same temperatures, respectively. The first two weight loss steps are also observed for these two samples at all temperatures; however, the amount of weight losses is low compared to EG$0 \mathrm{H}_{2} \mathrm{O}_{2}$ samples. In Figures $6 \mathrm{~b}$ and $6 \mathrm{c}$, EG-5 $\mathrm{H}_{2} \mathrm{O}_{2}-25$ and $\mathrm{EG}-10 \mathrm{H}_{2} \mathrm{O}_{2}-25$ samples confirm $\sim 27 \%$ and $\sim 14 \%$ of total weight loss, respectively, and they show the similar weight loss trend as EG$\mathrm{OH}_{2} \mathrm{O}_{2}$ at higher exfoliation temperatures. It is also evident that the second step of weight loss decreases with increasing the exfoliation temperature for both $\mathrm{EG}-5 \mathrm{H}_{2} \mathrm{O}_{2}$ and $\mathrm{EG}-10 \mathrm{H}_{2} \mathrm{O}_{2}$ samples. Because the second weight loss step is assigned to the removal of residual oxygen functional groups, this result indicates that the addition of $\mathrm{H}_{2} \mathrm{O}_{2}$ and the increase of reaction temperature during electrochemical exfoliation greatly decreases the oxygen-containing 
functional groups, which improves the thermal stability of the EGs. Table 2 compares the weight percentage of calculated oxygen functional groups present in the temperature range from 150 to $400{ }^{\circ} \mathrm{C}$ based on the weight loss measurement. It also should be noted that the third step of weight losses due to the unstable carbon remaining in the structure is observed at over $600^{\circ} \mathrm{C}$ for both EG- $0 \mathrm{H}_{2} \mathrm{O}_{2}$ and EG-5 $\mathrm{H}_{2} \mathrm{O}_{2}$ seen in Figures $6 \mathrm{a}$ and $6 \mathrm{~b}$. However, the third weight loss step can hardly be seen for the EG- $10 \mathrm{H}_{2} \mathrm{O}_{2}$ samples shown in Figure 6c. As the exfoliation temperature increases, the thermal stability of $\mathrm{EG}-10 \mathrm{H}_{2} \mathrm{O}_{2}$ increases; nevertheless, it does not show any unstable carbon weight loss at any exfoliation temperature. It is clear that the addition of $\mathrm{H}_{2} \mathrm{O}_{2}$ reduces the amount of the unstable carbon during the electrochemical exfoliation.

To observe this even precisely, Figure 6d was drawn in a narrow range to show the weight loss corresponding to the removal of the unstable carbon for $\mathrm{EG}-0 \mathrm{H}_{2} \mathrm{O}_{2}, \mathrm{EG}-5 \mathrm{H}_{2} \mathrm{O}_{2}$ and $\mathrm{EG}-10 \mathrm{H}_{2} \mathrm{O}_{2}$ synthesized at $95^{\circ} \mathrm{C}$. The unstable carbon can be observed in graphene synthesized by Brodie ${ }^{39}$ method. In this study, EG- $10 \mathrm{H}_{2} \mathrm{O}_{2}-95$ sample shows the highest thermal stability with having extremely low $(<1 \%)$ amount of unstable carbon in the structure.

The advantage of the addition of $\mathrm{H}_{2} \mathrm{O}_{2}$ and higher temperature electrochemical exfoliation can be understood as follows. It is known that $\mathrm{OH}^{-}$and $\mathrm{O}_{2}{ }^{2-}$ interact with graphite edges and grain boundaries, and this helps to expand carbon layers. ${ }^{20}$ The reactions 1 and 2 explain how the hydroxyl ions $\left(\mathrm{OH}^{-}\right)$come to the solution from the reduction of water at negative electrode, and the peroxide ions $\left(\mathrm{O}_{2}{ }^{2-}\right)$ are formed when $\mathrm{H}_{2} \mathrm{O}_{2}$ is added. ${ }^{19} \mathrm{SO}_{2}$ and $\mathrm{O}_{2}$ gases are also produced from the residual $\mathrm{SO}_{4}{ }^{2-}$ ions and water oxidation, respectively, during the process shown below in the reactions 3 and $4 .{ }^{19,35}$ These gases intercalate with graphite layers and peel each layer off by applying force on the layers. ${ }^{19}$ A possible exfoliation process is shown in a schematic representation in Figure 7.

$$
\begin{aligned}
& 4 \mathrm{H}_{2} \mathrm{O}+4 \mathrm{e}^{-} \longrightarrow 2 \mathrm{H}_{2}+4 \mathrm{OH}^{-} \\
& \mathrm{H}_{2} \mathrm{O}_{2}+2 \mathrm{OH}^{-} \longrightarrow \mathrm{O}_{2}{ }^{2-}+2 \mathrm{H}_{2} \mathrm{O} \\
& \mathrm{SO}_{4}{ }^{2-}+4 \mathrm{H}^{+}+4 \mathrm{e}^{-} \longrightarrow \mathrm{SO}_{2}+2 \mathrm{H}_{2} \mathrm{O} \\
& \mathrm{H}_{2} \mathrm{O} \longrightarrow \mathrm{OH}^{-}+\mathrm{H}^{+} \longrightarrow \mathrm{O}+2 \mathrm{H}^{+} \longrightarrow \frac{1}{2} \mathrm{O}_{2}
\end{aligned}
$$

$\mathrm{OH}^{-}$has low nucleophilicity. Thus, it does not interact with graphite effectively. This leads to less chance of intercalation of $\mathrm{SO}_{2}$ and $\mathrm{O}_{2}$ in the absence of $\mathrm{H}_{2} \mathrm{O}_{2}$. Less interaction of these gasses with graphite layers causes the remaining of some unstable carbons. However, the oxidation of water happens more frequently at a higher temperature, which leads to less amount of $\mathrm{OH}^{-}$in the solution. The amount of oxygen functional groups decreases drastically with increasing exfoliation temperature due to the decrease of $\mathrm{OH}^{-}$; thus, the number of defects decreases as oxygen functional groups are one kind of defects. Peroxide ions are better nucleophilic than hydroxyl ions and, thus, $\mathrm{O}_{2}{ }^{2-}$ can interact with graphite effectively. However, the effectiveness of interaction of $\mathrm{O}_{2}{ }^{2-}$ depends on the rate of the reaction 2. Kodepelly S. Rao et 
al. $^{20}$ showed that the exfoliation rate increases drastically with increasing the concentration of $\mathrm{H}_{2} \mathrm{O}_{2}$. For the addition of $5 \mathrm{~mL} \mathrm{H}_{2} \mathrm{O}_{2}$, the effectiveness of interaction of $\mathrm{O}_{2}{ }^{2-}$ is still low enough to produce unstable carbons due to the slower rate of the reaction. The rate of reaction increases with increasing temperature and, thus, the amount of $\mathrm{O}_{2}{ }^{2-}$ increases with increasing exfoliation temperature which eventually leads to the presence of less amount of unstable carbon in graphene. On the other hand, for the addition of $10 \mathrm{~mL} \mathrm{H}_{2} \mathrm{O}_{2}$ the rate of reaction increases due to the increment of $\mathrm{H}_{2} \mathrm{O}_{2}$ concentration in the solution, and it produces enough $\mathrm{O}_{2}{ }^{2-}$ to increase the effectiveness of intercalation with graphite.

$\mathrm{OH}^{-}$produces most oxygen functional groups in the layers during intercalation with graphite, and $\mathrm{O}_{2}{ }^{2-}$ produces fewer amounts of oxygen functional groups due to its high nucleophilic behavior. In the absence of $\mathrm{H}_{2} \mathrm{O}_{2}$, oxidation of water increases with increasing temperature, which leads to fewer amounts of $\mathrm{OH}^{-}$, and this process yields fewer amounts of oxygen functional groups. For 5 $\mathrm{mL} \mathrm{H}_{2} \mathrm{O}_{2}$ addition both $\mathrm{OH}^{-}$and $\mathrm{O}_{2}{ }^{2-}$ participate in producing oxygen functional groups. As the exfoliation temperature increases, the amount of $\mathrm{OH}^{-}$decreases due to a higher water oxidation rate. Although the amount of $\mathrm{OH}^{-}$decreases at the same rate for both cases $(0 \mathrm{~mL}$ and $5 \mathrm{~mL}$ of $\mathrm{H}_{2} \mathrm{O}_{2}$ ) there is still $\mathrm{OH}^{-}$left along with $\mathrm{O}_{2}{ }^{2-}$ for $5 \mathrm{~mL} \mathrm{H}_{2} \mathrm{O}_{2}$ case, and both $\mathrm{OH}^{-}$and $\mathrm{O}_{2}{ }^{2-}$ produce oxygen functional groups during interaction with graphite. For $10 \mathrm{~mL} \mathrm{H}_{2} \mathrm{O}_{2}$ addition, only $\mathrm{O}_{2}{ }^{2-}$ produces oxygen functional groups. Thus, the amount of oxygen functional groups is the lowest in this case.

\subsection{TEM analysis:}

TEM analysis was done on electrochemically exfoliated graphene to observe the number of layers shown in Figure 8. The TEM images of EG synthesized at $50^{\circ} \mathrm{C}$ with and without the addition of $\mathrm{H}_{2} \mathrm{O}_{2}$ were taken at the same magnification $(\times 4000)$ shown in Figure 8a-c. Typically it was observed that multi-layer $(\geq 3)$ graphene was obtained for the samples without the addition of $\mathrm{H}_{2} \mathrm{O}_{2}$. Figure 8a shows a usual TEM image of three layers of graphene synthesized without the addition of $\mathrm{H}_{2} \mathrm{O}_{2}$ at $50^{\circ} \mathrm{C}$. Many wrinkles of graphene sheets are observed in the samples without the addition of $\mathrm{H}_{2} \mathrm{O}_{2}$. Figure $8 \mathrm{~b}$ and $8 \mathrm{c}$ show TEM images of double-layer or overlap of two single-layer graphene sheets with uniform contrast for both EG-5 $\mathrm{H}_{2} \mathrm{O}_{2}-50$ and $\mathrm{EG}-10 \mathrm{H}_{2} \mathrm{O}_{2}$ 50 samples, respectively. The uniform or homogeneous contrast in TEM images indicates less folded or crumpled regions within these graphene sheets. As $\mathrm{H}_{2} \mathrm{O}_{2}$ was added, it is clear that the number of graphene sheet layers decreased due to the interaction of highly nucleophilic $\mathrm{O}_{2}{ }^{2-}$. In Figure 8d, TEM image of EG- $10 \mathrm{H}_{2} \mathrm{O}_{2}-95$ sample shows a double-layer graphene at a magnification of $\times 30 \mathrm{~K}$, and these graphene layers have fewer wrinkles. The selected area electron diffraction (SAED) was recorded and shown with index in the inset of Figure 8d. It shows the typical six-fold symmetry corresponding to the hexagonal carbon lattice in graphene. The electron diffraction spots were indexed/labeled using Miller-Bravis (hkil) indices. An identification method of graphene layers by electron diffraction pattern was proposed by Meyer et al. ${ }^{40}$ using the intensity ratio of the $\{1-210\}$ and $\{1-100\}$ spots. The ratio of $\mathrm{I}(1-210) / \mathrm{I}(1-100)$ for $\mathrm{EG}-10 \mathrm{H}_{2} \mathrm{O}_{2}-95$ is 0.61 shown in Figure 9 and confirms that as-synthesized graphene is a 
single layer in fact. Kodepelly S. Rao et al. ${ }^{20}$ reported getting three or more layers of graphene sheets, using electrochemical exfoliation method, by adding $\mathrm{H}_{2} \mathrm{O}_{2}$ in the electrolyte solution kept at room temperature. In our experiment, double-layer or overlap of two single-layer graphene sheets was obtained due to the increase of the electrolyte solution temperature during the electrochemical exfoliation. The heating of electrolyte solution causes the increase of the rate of reaction of hydrogen peroxide with hydroxyl ion, which helps to exfoliate graphene layers more efficiently as discussed above.

\section{Conclusion:}

The experimented electrochemical exfoliation method at elevated temperatures has several major advantages, such as (i) simple operation setup, (ii) ecofriendly, (iii) one step method, (iv) low temperature (maximum $95{ }^{\circ} \mathrm{C}$ ). The layer number of the graphene, the number of defects and the amount of oxygen functional groups can be controlled using a different amount of $\mathrm{H}_{2} \mathrm{O}_{2}$ at different temperatures. The amount of oxygen functional groups decreases with increasing the exfoliation temperature of electrolyte and the amount of $\mathrm{H}_{2} \mathrm{O}_{2}$ addition in the electrolyte solution. The number of defects decreases as well due to the increase of the exfoliation temperature and the concentration of $\mathrm{H}_{2} \mathrm{O}_{2}$ in the solution. Increasing the concentration of $\mathrm{H}_{2} \mathrm{O}_{2}$ produces fewer amounts of unstable carbon, and as for the addition of $10 \mathrm{~mL} \mathrm{H}_{2} \mathrm{O}_{2}$, there was less than $1 \%$ unstable carbon in graphene. Increasing both the exfoliation temperature and the concentration of $\mathrm{H}_{2} \mathrm{O}_{2}$ causes the decrease in layer number of graphene. Electrochemical exfoliation of graphite at $95^{\circ} \mathrm{C}$ with the addition of $10 \mathrm{~mL} \mathrm{H}_{2} \mathrm{O}_{2}$ produced low-defect, double-layer or overlap of two single-layer graphene. This research showed a crucial role of both temperature and $\mathrm{H}_{2} \mathrm{O}_{2}$ addition in producing high-quality graphene, which is significant for future applications.

\section{Acknowledgements:}

This work is supported by the National Science Foundation (NSF CHE-1362251) and the American Chemical Society Petroleum Research Fund (\#52323). The use of TEM facilities at the Center of Excellence in Materials Science and Engineering at Youngstown State University are gratefully acknowledged. 


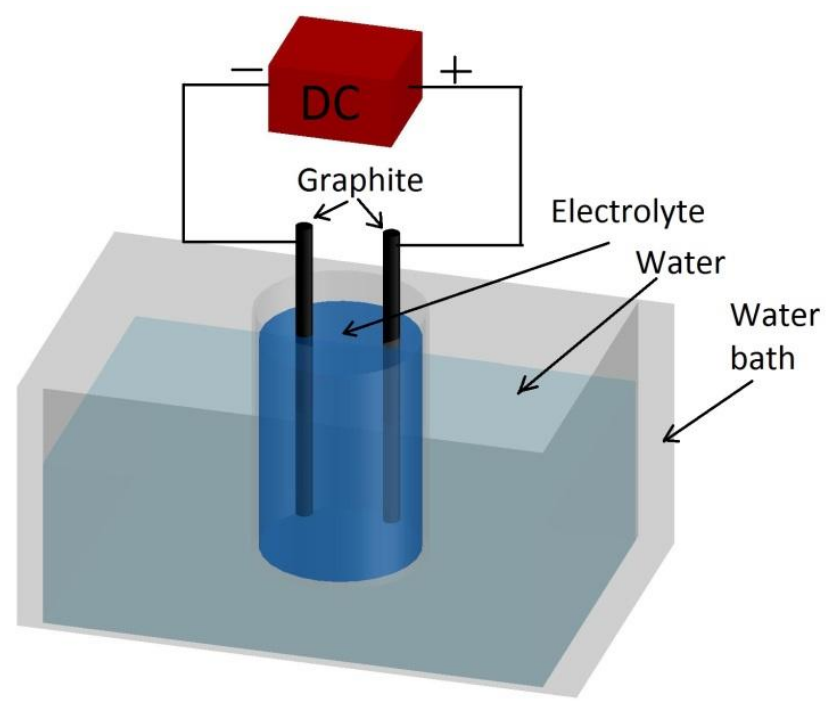

Figure 1. Schematic of a typical electrochemical exfoliation process to prepare graphene. 


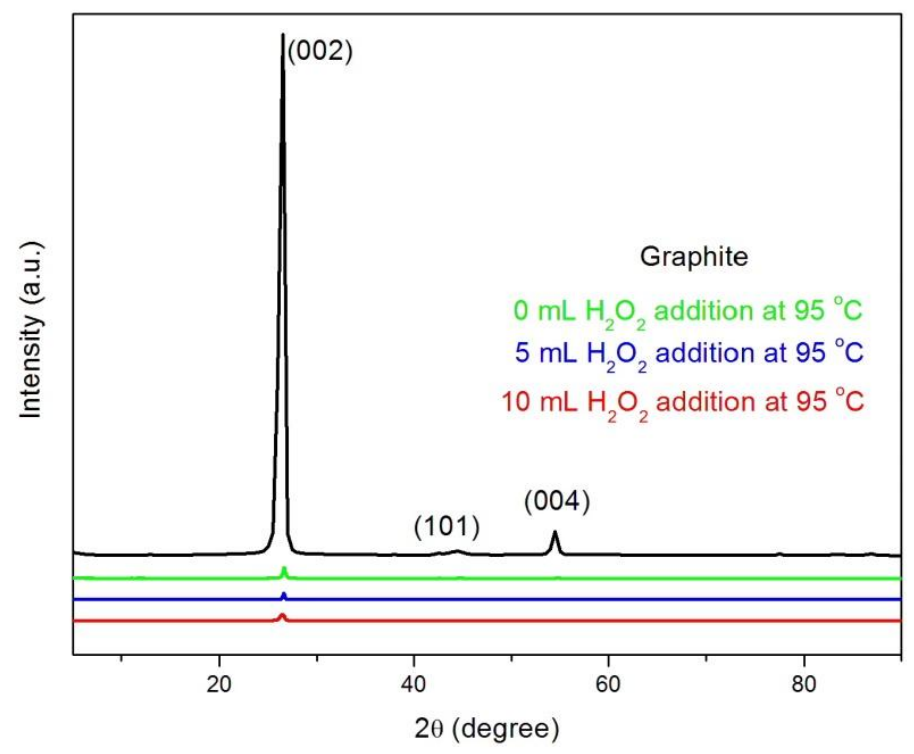

Figure 2. XRD patterns of graphite, and exfoliated graphene synthesized at $95^{\circ} \mathrm{C}$ with the addition of 0,5 and $10 \mathrm{~mL}$ of $\mathrm{H}_{2} \mathrm{O}_{2}$. 

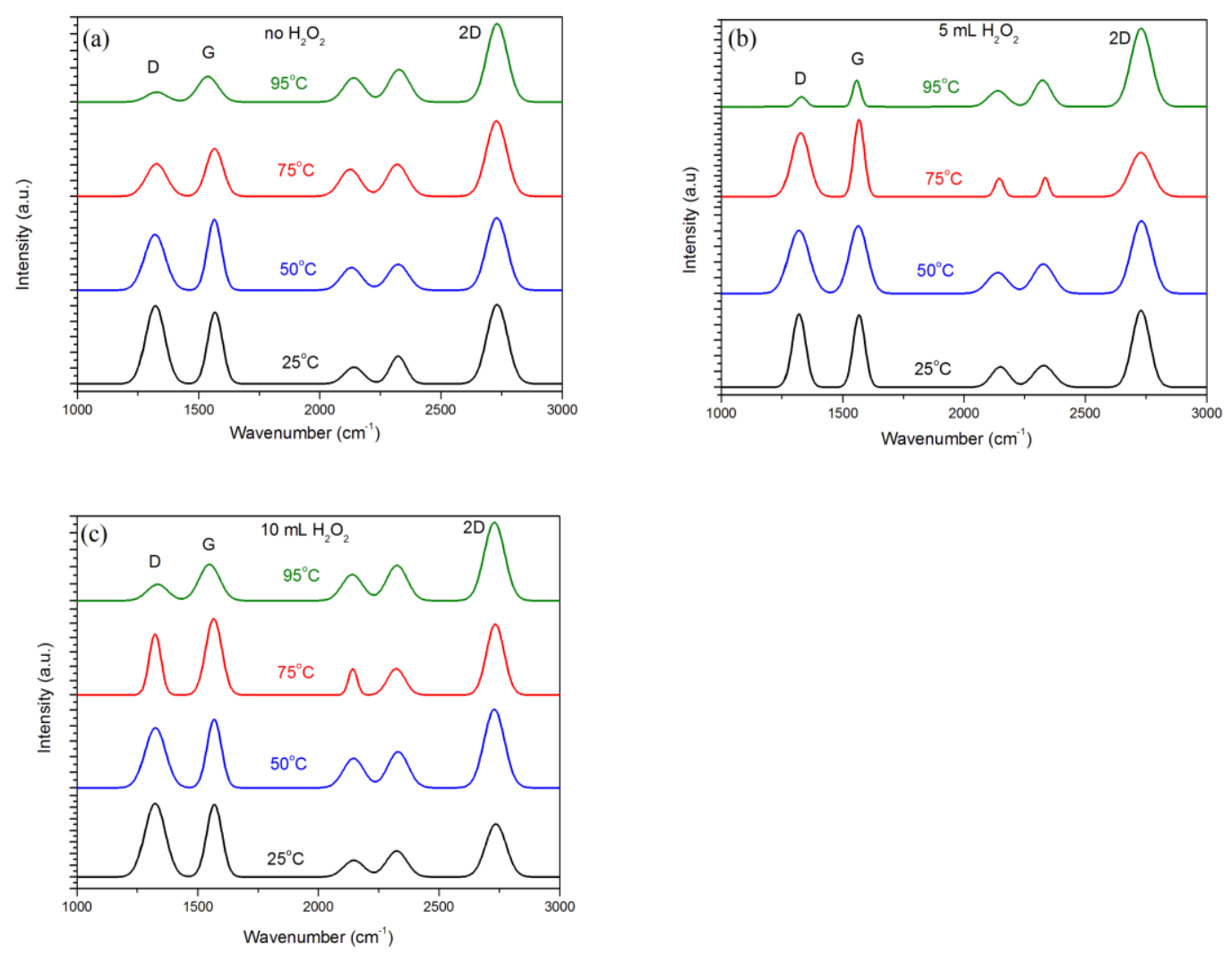

Figure 3. Raman spectra of the exfoliated graphenes synthesized using electrochemical exfoliation (a) without the addition of $\mathrm{H}_{2} \mathrm{O}_{2}$ and with the addition of (b) $5 \mathrm{~mL} \mathrm{H}_{2} \mathrm{O}_{2}$ and (c) 10 $\mathrm{mL} \mathrm{H}_{2} \mathrm{O}_{2}$ at different temperatures in the range of 25 to $95^{\circ} \mathrm{C}$. 

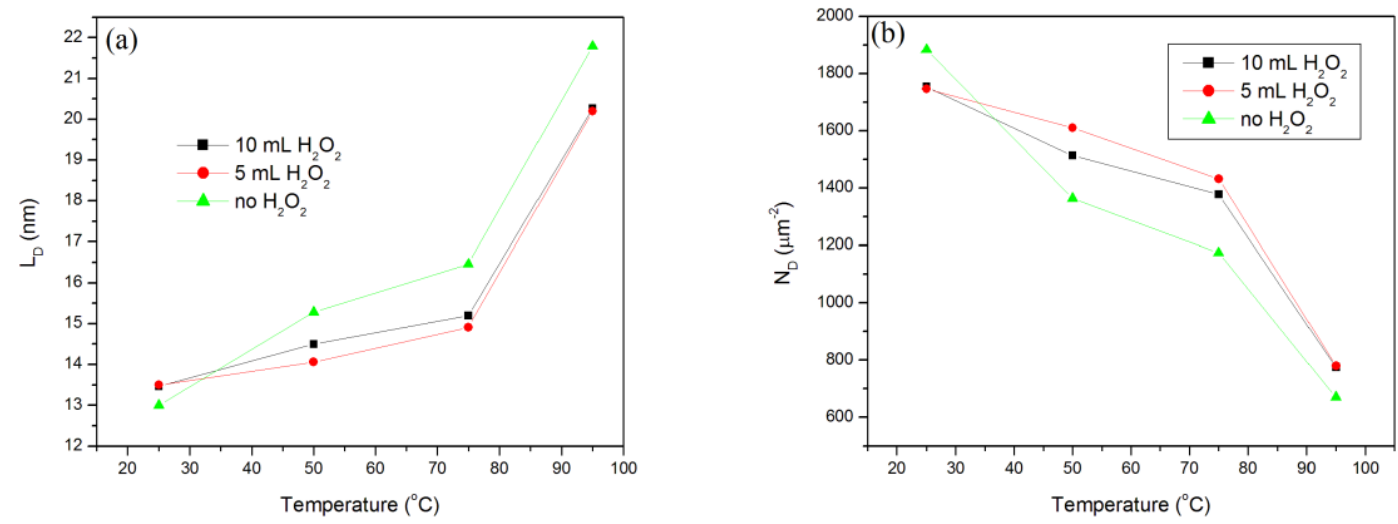

Figure 4. Comparison of (a) the mean distances between defects and (b) the number of defects in the exfoliated graphene synthesized with and without the addition of $\mathrm{H}_{2} \mathrm{O}_{2}$ at different temperatures. 


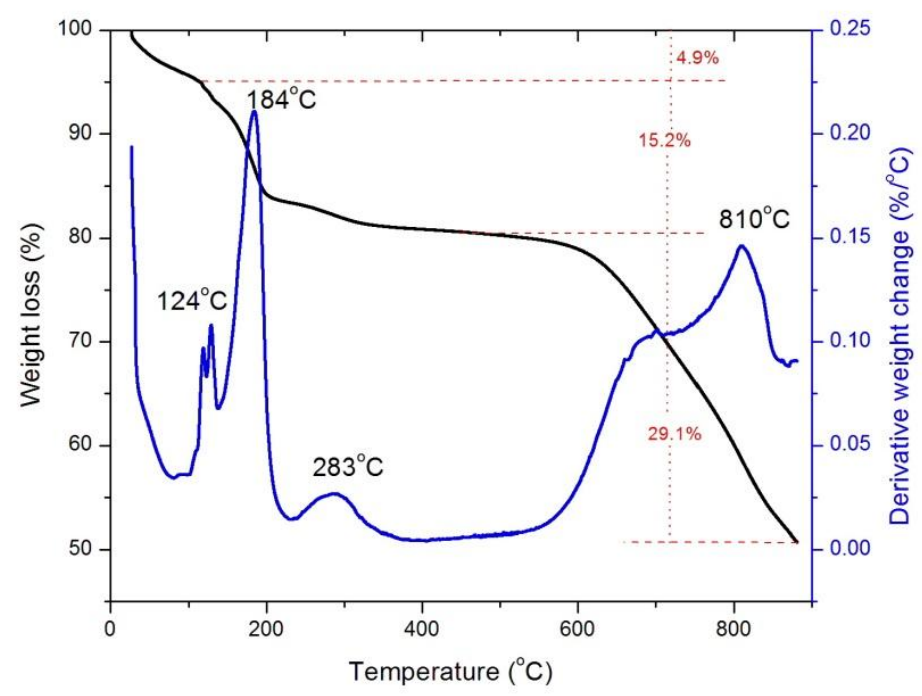

Figure 5. TGA and DTG curves of the EG synthesized at $25^{\circ} \mathrm{C}$ without the addition of $\mathrm{H}_{2} \mathrm{O}_{2}$. Black and blue profiles represent the weight loss and first derivative of weight loss with respect to temperature, respectively. 

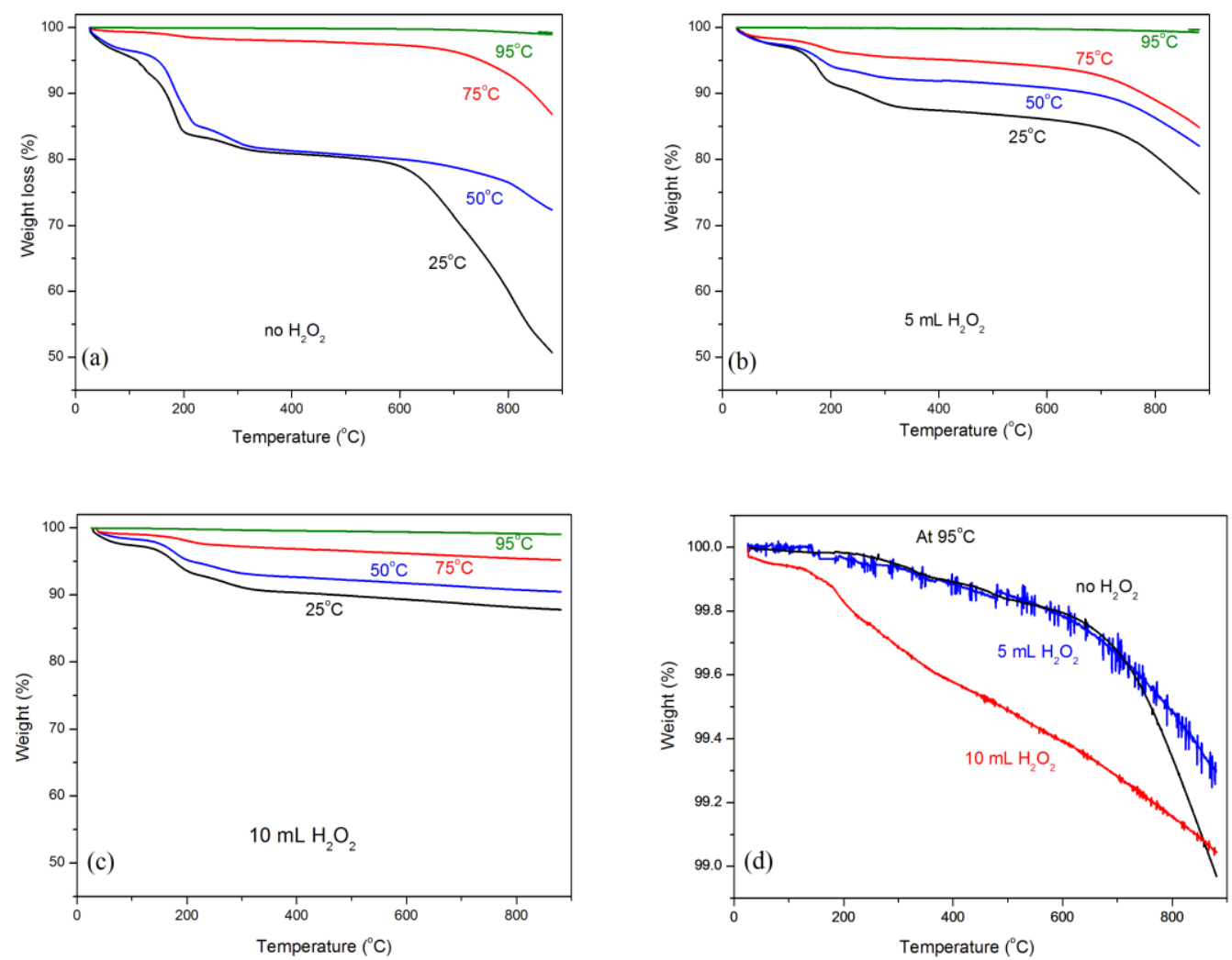

Figure 6. TGA curves for the exfoliated graphene synthesized using electrochemical exfoliation (a) without addition of $\mathrm{H}_{2} \mathrm{O}_{2}$ and with addition of (b) $5 \mathrm{~mL} \mathrm{H}_{2} \mathrm{O}_{2}$ and (c) $10 \mathrm{~mL} \mathrm{H}_{2} \mathrm{O}_{2}$ at different temperatures in the range of 25 to $95^{\circ} \mathrm{C}$. (d) TGA curves for the graphene synthesized at $95^{\circ} \mathrm{C}$ with and without addition of $\mathrm{H}_{2} \mathrm{O}_{2}$. 


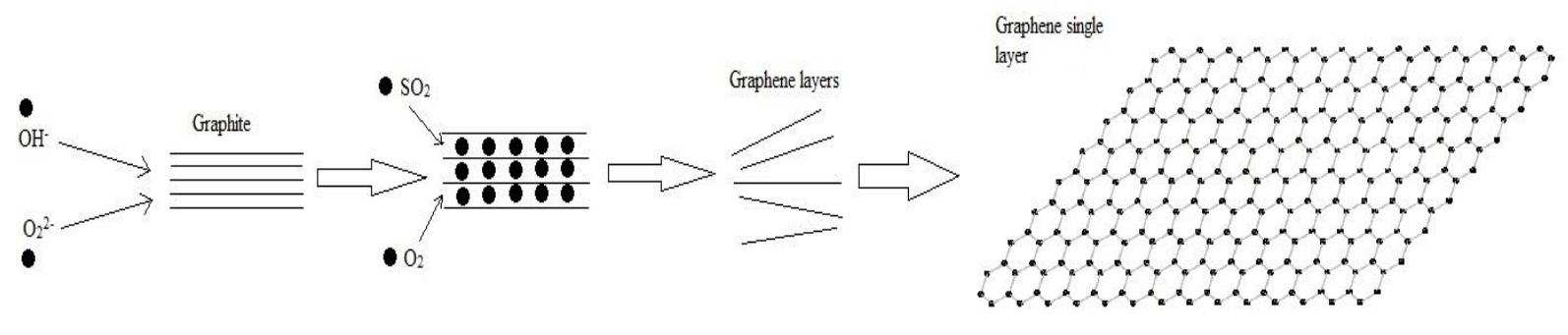

Figure 7. Schematic representation of the proposed exfoliation process. 


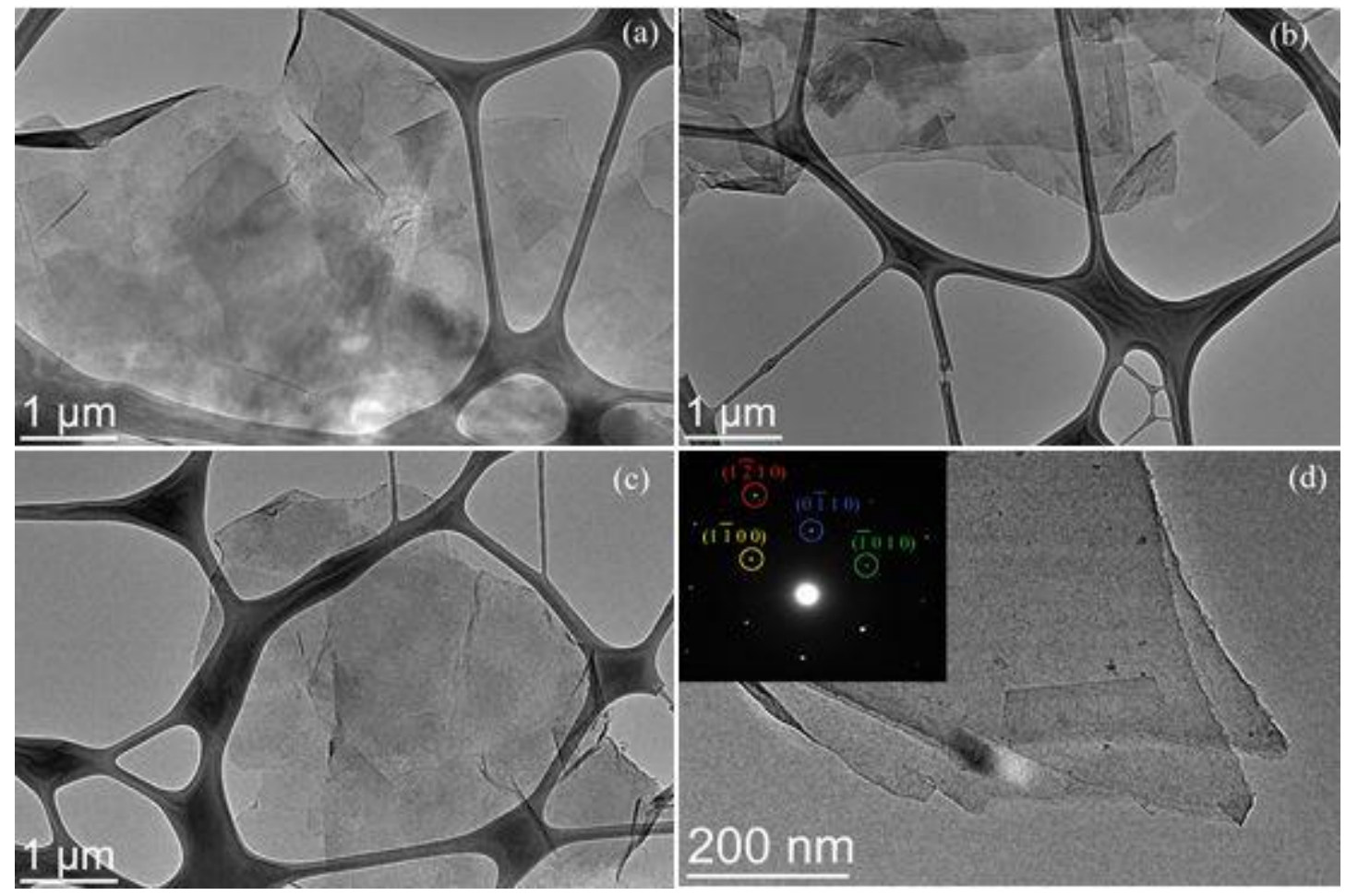

Figure 8. TEM images of the exfoliated graphenes synthesized using electrochemical exfoliation at $50^{\circ} \mathrm{C}$ (a) without the addition of $\mathrm{H}_{2} \mathrm{O}_{2}$ and with the addition of (b) $5 \mathrm{~mL} \mathrm{H}_{2} \mathrm{O}_{2}$ and (c) $10 \mathrm{~mL}$ $\mathrm{H}_{2} \mathrm{O}_{2}$. (d) Electrochemical exfoliation at $95^{\circ} \mathrm{C}$ with the addition of $10 \mathrm{~mL} \mathrm{H}_{2} \mathrm{O}_{2}$ and the corresponding selected area electron diffraction pattern (inserted). 


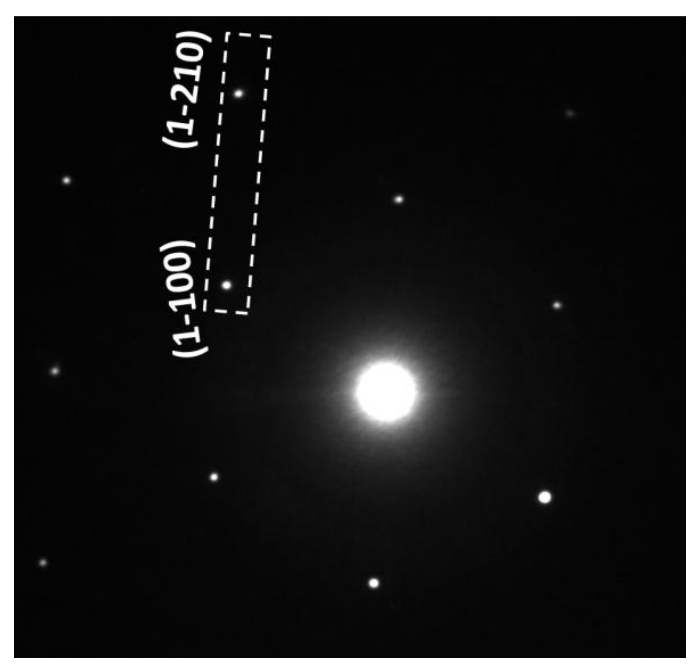

(a)

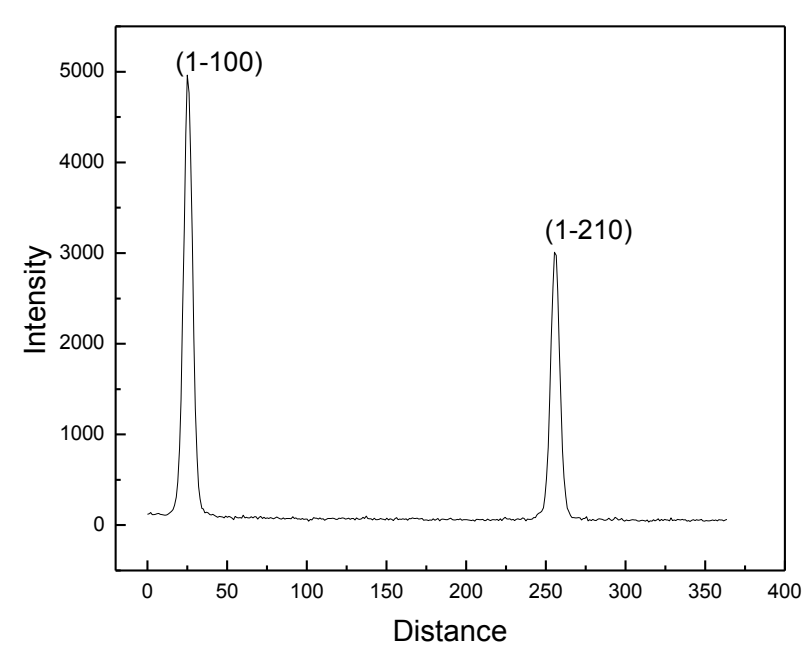

(b)

Figure 9. Selected area diffraction pattern (a) of the EG sample synthesized at $95{ }^{\circ} \mathrm{C}$ with the addition of $10 \mathrm{~mL} \mathrm{H}_{2} \mathrm{O}_{2}$ and (b) diffraction intensity $\mathrm{I}(1-100)$ and $\mathrm{I}(1-210)$ of the (1-100) and (1210) diffraction spots. 
Table 1. The amount of exfoliated graphene synthesized at different conditions.

\begin{tabular}{|c|c|c|c|}
\hline $\begin{array}{c}\text { Temperature } \\
\left({ }^{\circ} \mathrm{C}\right)\end{array}$ & $\begin{array}{c}\mathbf{0} \mathrm{mL} \mathrm{H}_{2} \mathrm{O}_{2} \\
(\mathrm{mg})\end{array}$ & 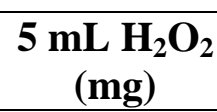 & 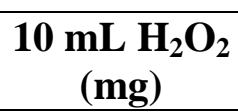 \\
\hline 25 & 223 & 240 & 276 \\
\hline 50 & 215 & 232 & 265 \\
\hline 75 & 201 & 225 & 247 \\
\hline 95 & 182 & 212 & 228 \\
\hline
\end{tabular}


Table 2. The percentage of oxygen functional groups present in the temperature range from 150 to $400^{\circ} \mathrm{C}$ in the EGs synthesized at different exfoliation temperatures with and without the addition of $\mathrm{H}_{2} \mathrm{O}_{2}$.

\begin{tabular}{|c|c|c|c|}
\hline $\begin{array}{c}\text { Temperature } \\
\left({ }^{\circ} \mathrm{C}\right)\end{array}$ & $\begin{array}{c}\mathbf{O} \mathrm{mL}_{(\%)}^{\mathrm{H}_{2} \mathrm{O}_{2}} \\
(\%)\end{array}$ & $\begin{array}{c}5 \mathbf{~ m L ~ \mathrm { H } _ { 2 } \mathbf { O } _ { 2 }} \\
(\%)\end{array}$ & $\begin{array}{c}1 \% \mathrm{~mL} \mathrm{H}_{2} \mathrm{O}_{2} \\
\%\end{array}$ \\
\hline 25 & 15.22 & 9.35 & 6.66 \\
\hline 50 & 14.80 & 5.46 & 5.26 \\
\hline 75 & 0.93 & 2.10 & 1.44 \\
\hline 95 & 0.00 & 0.00 & 0.17 \\
\hline
\end{tabular}




\section{References:}

1 Geim, A. K.; Novoselov, K. S. The rise of graphene. Nat. Mater. 2007, 6, 183 - 191.

2 Huo, J.; Shao, Y.; Ellis, M. W.; Moore, R. B.; Yi, B. Graphene-based electrochemical energy conversion and storage: fuel cells, supercapacitors and lithium ion batteries. Phys. Chem. Chem. Phys., 2011, 13, 15384-15402.

3 Park, S.; Ruoff, R. S. Chemical methods for the production of graphenes. Nat. Nanotechnol. 2009, 4, $217-224$.

4 Shuvo, M. A. I; Khan, M. A. R.; Karim, H.; Morton, P.; Wilson, T.; Lin, Y. Investigation of modified graphene for energy storage applications. ACS Appl. Mater. Interfaces, 2013, 5, 78817885.

5 Zhu, J.; Yang, D.; Yin, Z.; Yan, Q.; Zhang, H. Graphene and graphene-based materials for energy storage applications. Small, 2014, 10, 3480-3498.

6 Wu, D. Q.; Zhang, F.; Liang, H. W.; Feng, X. L. Nanocomposites and macroscopic materials: assembly of chemically modified graphene sheets. Chem. Soc. Rev., 2012, 41, 6160-6177.

7 Kim, K.; Choi, J. Y.; Kim, T.; Cho, S. H.; Chung, H. J. A role of graphene in silicon-based semiconductor devices. Nature, 2011, 479, 338-344.

8 Gilje, S.; Han, S.; Wang, M.; Wang, K. L.; Kaner, R. B. A chemical route to graphene for device applications. Nano Lett., 2007, 7, 3394-3398.

9 Arsat, R.; Breedon, M.; Shafiei, M.; Spizziri, P. G.; Gilje, S.; Kaner, R. B.; Zadeh, K. K.; Wlodarski, W. Graphene-like nano sheets for surface acoustic wave gas sensor applications. Chem. Phys. Lett., 2009, 467, 344-347.

10 Ruoff, R. S. Personal perspectives on graphene: New graphene-related materials on the horizon. MRS Bulletin, 2012, 37, 1314-1318.

11 Hawaldar, R.; Merino, P.; Correia, M. R.; Bdikin, I.; Grácio, J.; Méndez, J.; Martín-Gago, J. A.; Singhet, M. K. Large-area high-throughput synthesis of monolayer graphene sheet by hot filament thermal chemical vapor deposition. Sci. Rep. 2012, 2, 682-690.

12 Yoon, J. C., Lee, J. S., Kim, S. I., Kim, K. H.; Jang, J. H. Three-dimensional graphene nanonetworks with high quality and mass production capability via precursor-assisted chemical vapor deposition. Sci. Rep. 2013, 3, 1788-1795.

13 Bonaccorso, F.; Lombardo, A.; Hasan, T.; Suna, Z.; Colombob, L.; Ferraria, A. C. Production and processing of graphene and 2 d crystals. Mater. Today, 2012, 15, 564-589. 
14 Chabot, V.; Kim, B.; Sloper, B.; Tzoganakis, C.; Yu, A. High yield production and purification of few layer graphene by gum arabic assisted physical sonication. Sci. Rep. 2013, 3, 1378-1384.

15 Zhu, Y.; Murali, S.; Stoller, M. D.; Velamakanni, A.; Piner, R. D.; Ruoff, R. S. Microwave assisted exfoliation and reduction of graphite oxide for ultracapacitors. Carbon, 2010, 48, 2106 2122.

16 Chen, W.; Yan, L.; Bangal, P. R. Preparation of graphene by the rapid and mild thermal reduction of graphene oxide induced by microwaves. Carbon, 2010, 48, 1146 - 1152.

17 Dikin, D. A.; Stankovich, S.; Zimney, E. J.; Piner, R. D.; Dommett, G. H. B.; Evmenenko, G.; Nguyen, S. T.; Ruoff, R. S. Preparation and characterization of graphene oxide paper.

Nature, 2007, 448, 457-460.

18 Marcano, D. C.; Kosynkin, D. V.; Berlin, J. M.; Sinitskii, A.; Sun, Z.; Slesarev, A.; Alemany, L. B.; Lu, W.; Tour, J. M. Improved Synthesis of Graphene Oxide. ACS Nano, 2010, 4, 4806 4814.

19 Parvez, K.; Wu, Z. S.; Li, R.; Liu, X.; Graf, R.; Feng, X.; Mullen, K. Exfoliation of Graphite into Graphene in Aqueous Solutions of Inorganic Salts. J. Am. Chem. Soc., 2014, 136, 60836091.

20 Rao, K. S.; Senthilnathan, J.; Liu, Y. F.; Yoshimura, M. Role of Peroxide Ions in Formation of Graphene Nanosheets by Electrochemical Exfoliation of Graphite. Sci. Rep., 2014, 4, 4237.

21 Kim, J.; Ishihara, M.; Koga, Y.; Tsugawa, K.; Hasegawa, M.; Iijima, S. Low-temperature synthesis of large-area graphene-based transparent conductive films using surface wave plasma chemical vapor deposition. Appl. Phys. Lett. 2011, 98, 091502.

22 Peng, S.; Fan, X.; Li, S.; Zhang, J. Green synthesis and characterization of graphite oxide by orthogonal experiment. J. Chil. Chem. Soc. 2013, 58, 2213-2217.

23 Geng, X.; Guo, Y.; Li, D.; Li, W.; Zhu, C.; Wei, X.; Chen, M.; Gao, S.; Qiu, S.; Gong, Y.; Wu, L.; Long, M.; Sun, M.; Pan, G.; Liu, L. Interlayer catalytic exfoliation realizing scalable production of large-size pristine few-layer graphene. Sci. Rep. 2013, 3, 1134.

24 Zhao, M.; Tang, J.; Cheng, Q.; Xu, G.; Cui, P.; Qing, L.C. Few-layer graphene obtained by electrochemical exfoliation of graphite. Chem. Phys. Lett. 2013, 572, 61-65.

25 Zhao, H.; Zhao, T. S. Graphene sheets fabricated from disposable paper cups as a catalyst support material for fuel cells. J. Mater. Chem. A 2013, 1, 183-187.

26 Wazir, A. H.; Kundi, I. W. Synthesis of graphene nano sheets by the rapid reduction of electrochemically exfoliated graphene oxide induced by microwaves. J. Chem. Soc. Pak. 2016, $38,11-16$. 
27 Sun, X.; Xie, M.; Wang, G.; Sun, H.; Cavanagh, A. S.; Travis, J. J.; George, S. M.; Lian J. Atomic layer deposition of $\mathrm{TiO} 2$ of graphene for supercapacitors. J. Electrochem. Soc. 2012, 159, A364-A369.

28 Eckmann, A.; Felten, A.; Mishchenko, A.; Britnell, L.; Krupke, R.; Novoselov, K. S.; Casiraghi, C. Probing the nature of defects in graphene by Raman spectroscopy. Nano Lett. 2012, 12, 3925-3930.

29 Ferrari, A. C.; Meyer, J. C.; Scardaci, V.; Casiraghi, C.; Lazzeri, M.; Mauri, F.; Piscanec, S.; Jiang, D.; Novoselov, K. S.; Roth, S.; Geim, A. K. Raman spectrum of graphene and graphene layers, Phys. Rev. Lett. 2006, 97, 187401.

30 Ferrari, A. C.; Robertson, J. Raman spectroscopy of amorphous, nanostructured, diamond-like carbon, and nanodiamond. Phil. Trans. R. Soc. Lond. A 2004, 362, 2477-2512.

31 Andrade, N. F.; Vasconcelos, T. L.; Gouvea, C. P.; Archanjo, B. S.; Achete, C. A.; Kim, Y. A.; Endo, M.; Fantini, C.; Dresselhaus, M. S.; Filho, A. G. S. Linear carbon chains encapsulated in multiwall carbon nanotubes: Resonance Raman spectroscopy and transmission electron microscopy studies. Carbon 2015, 90, 172-180.

32 Yoon, D.; Moon, H.; Cheong, H. Variations in the Raman spectrum as a function of the number of graphene layers. J. Korean Phys. Soc. 2009, 55, 1299-1303.

33 Wang, Z.; Liu, J.; Wang, W. et al. Aqueous phase preparation of graphene with low defect density and adjustable layers, Chem. Commun. 2013, 49, 10835-10837.

34 Buglionea, L.; Chnga, E. L. K.; Ambrosia, A.; Soferb, Z.; Pumera, M. Graphene materials preparation methods have dramatic influence upon their capacitance. Electrochem. Commun. 2012, 14, 5-8.

35 Beck, F.; Jiang, J.; Krohn, H. Potential oscillations during galvanostatic overoxidation of graphite in aqueous sulphuric acids. J. Electroanal. Chem. 1995, 389, 161-165.

36 Chen, H.; Muller, M. B.; Gilmore, K. J.; Wallace, G. G.; Li, D. Mechanically strong, electrically conductive, and biocompatible graphene paper. Adv. Mater. 2008, 20, 3557-3561.

37 Park, S.; An, J.; Potts, J. R.; Velamakanni, A.; Murali, S.; Ruoff, R. S. Hydrazine-reduction of graphite- and graphene oxide. Carbon 2011, 49, 3019-3023.

38 Naebe, M.; Wang, J.; Amini, A.; Khayyam, H.; Hameed, N.; Li, L. H.; Chen, Y.; Fox, B. Mechanical property and structure of covalent functionalized graphene/epoxy nanocomposites. Sci. Rep. 2014, 4, 4375.

39 Botas, C.; Alvarez, P.; Blanco, P.; Granda, M.; Blanco, C.; Santamaria, R.; Romasanta, L. J.; Verdejo, R.; Lopez-Manchado, M. A.; Menendez, R. Graphene materials with different 
structures prepared from the same graphite by the Hummers and Brodie methods. Carbon 2013, $65,156-164$.

40 Meyer, J. C.; Geim, A. K.; Katsnelson, M. I.; Novoselov, K. S.; Obergfell, D.; Roth, S.; Girit, C.; Zettl, A. On the roughness of single- and bi-layer graphene membranes. Solid State Comm., 2007, 143, 101-109. 